\title{
The Y chromosome as a regulatory element shaping immune cell transcriptomes and susceptibility to autoimmune disease
}

\author{
Laure K. Case, ${ }^{1}$ Emma H. Wall, ${ }^{1}$ Julie A. Dragon, ${ }^{2}$ Naresha Saligrama, ${ }^{1}$ \\ Dimitry N. Krementsov, ${ }^{1}$ Mohamad Moussawi, ${ }^{3}$ James F. Zachary, ${ }^{4}$ \\ Sally A. Huber, ${ }^{3}$ Elizabeth P. Blankenhorn, ${ }^{5}$ and Cory Teuscher ${ }^{1,3,6}$
}

${ }^{1}$ Department of Medicine, ${ }^{2}$ Department of Microbiology and Molecular Genetics, ${ }^{3}$ Department of Pathology, University of Vermont, Burlington, Vermont 05405, USA; ${ }^{4}$ Department of Pathobiology, University of Illinois at Urbana-Champaign, Urbana, Illinois 61802, USA; ${ }^{5}$ Department of Microbiology and Immunology, Drexel University College of Medicine, Philadelphia, Pennsylvania 19129, USA

\begin{abstract}
Understanding the DNA elements that constitute and control the regulatory genome is critical for the appropriate therapeutic management of complex diseases. Here, using chromosome Y (ChrY) consomic mouse strains on the C57BL/ 6] (B6) background, we show that susceptibility to two diverse animal models of autoimmune disease, experimental allergic encephalomyelitis (EAE) and experimental myocarditis, correlates with the natural variation in copy number of Sly and Rbmy multicopy ChrY genes. On the B6 background, ChrY possesses gene regulatory properties that impact genome-wide gene expression in pathogenic $\mathrm{CD}^{+}{ }^{+} \mathrm{T}$ cells. Using a ChrY consomic strain on the SJL background, we discovered a preference for ChrY-mediated gene regulation in macrophages, the immune cell subset underlying the EAE sexual dimorphism in SJL mice, rather than $\mathrm{CD}^{+}{ }^{+} \mathrm{T}$ cells. Importantly, in both genetic backgrounds, an inverse correlation exists between the number of Sly and Rbmy ChrY gene copies and the number of significantly up-regulated genes in immune cells, thereby supporting a link between copy number variation of Sly and Rbmy with the ChrY genetic element exerting regulatory properties. Additionally, we show that ChrY polymorphism can determine the sexual dimorphism in EAE and myocarditis. In humans, an analysis of the $C D 4^{+} \mathrm{T}$ cell transcriptome from male multiple sclerosis patients versus healthy controls provides further evidence for an evolutionarily conserved mechanism of gene regulation by ChrY. Thus, as in Drosophila, these data establish the mammalian ChrY as a member of the regulatory genome due to its ability to epigenetically regulate genome-wide gene expression in immune cells.
\end{abstract}

[Supplemental material is available for this article.]

Sex-specific differences exist in many aspects of immune system physiology and contribute to the pathogenic differences in infectious disease observed between males and females (Pennell et al. 2012). Females tend to mount a more robust immune response against many infectious pathogens, leading to a better prognosis in disease outcome compared with males. However, the evolutionary advantage of this heightened immune response in females also contributes to their higher risk in developing autoimmune (AI) disease. While these sex differences in immunity are predominately linked to the differential effects of sex hormones on immune cells, genetic differences in sex chromosomes can also influence the immune response and susceptibility to disease (Ober et al. 2008; Arnold and Lusis 2012). Importantly, although the sex chromosome effect is often attributed to the difference in the number of $\mathrm{X}$ chromosomes (ChrX) between males and females, increasing evidence indicates that the mammalian Y chromosome (ChrY) contributes to immune responses and susceptibility to AI and infectious diseases (Teuscher et al. 2006; Spach et al. 2009; Robinson et al. 2011; Case et al. 2012; Charchar et al. 2012).

Like autosomal chromosomes, ChrX and ChrY are thought to have once been identical pairs that were free to recombine and

\footnotetext{
${ }^{6}$ Corresponding author

E-mail C.Teuscher@uvm.edu

Article published online before print. Article, supplemental material, and publication date are at http://www.genome.org/cgi/doi/10.1101/gr.156703.113.
}

exchange genetic material. Over the course of evolution, ChrY became unique from all other chromosomes due to the acquisition of a dominant sex-determining gene and subsequent chromosomal inversions that restricted recombination and led to its degradation (Charlesworth 1991; Gschwend et al. 2012). Although ChrY has evolved independently across different taxa, they share common genetic features that are specific to ChrY. For example, the relatively few protein-coding genes ChrY possesses are predominately male-specific genes acquired through transposition and translocation from other chromosomes (Skaletsky et al. 2003; Koerich et al. 2008). The remainder of ChrY is largely heterochromatic and composed of multicopy genes, repeat sequences, and transposable elements. Therefore, the nature of ChrY has led to the consensus that it is primarily composed of "junk" DNA whose contribution to phenotypic differences among the sexes is limited to sexual development and spermatogenesis. Indeed, until recently, large deletions in the long arm of the murine ChrY had no overt phenotypic effects except on spermatogenesis and sex ratio distortion (Tiepolo and Zuffardi 1976; Styrna et al. 1991a,b; Sun et al. 2013).

The first phenotypic evidence describing alternative functions for ChrY emerged from Drosophila studies linking ChrY polymorphism with behavior phenotypes (Stoltenberg and Hirsch 1997; Huttunen and Aspi 2003). Aside from its role in male development, the Drosophila ChrY differentially regulates the expression of autosomal and ChrX genes, including a preferential 
enrichment of genes associated with the immune response, by altering chromatin between the heterochromatic and euchromatic state, thereby influencing numerous complex phenotypes (Lemos et al. 2008, 2010; Piergentili 2010; Paredes et al. 2011). The ability of ChrY to alter chromatin dynamics and regulate gene expression is attributed to natural polymorphic variation in the multicopy ribosomal genes present on ChrY (Paredes et al. 2011; Zhou et al. 2012).

The mammalian ChrY can also moderate complex phenotypes not typically associated with this chromosome (Monahan and Maxson 1998; Chen et al. 2013). In mice, genetic variation in ChrY influences susceptibility of male C57BL/6J (B6) mice to experimental allergic encephalomyelitis (EAE), the animal model of multiple sclerosis (MS), as well as the EAE sexual dimorphism observed in the SJL/J mouse strain (Teuscher et al. 2006; Spach et al. 2009). Natural variation in ChrY also impacts the mortality rate of B6 mice following infection with coxsackievirus B3 (CVB3) and the basal levels of invariant natural killer T cells independently of the sex determining region of ChrY (Sry) expression level polymorphisms or differences in testosterone levels (Case et al. 2012). Furthermore, in humans, a recent study on coronary artery disease revealed a link between disease susceptibility and Haplogroup I of the male-specific region of human ChrY (Charchar et al. 2012). However, the mechanism whereby natural genetic variation in the mammalian ChrY influences susceptibility to disease is unknown and is thus the focus of this study.

Here, we show that susceptibility to two diverse animal models of AI disease correlates with the natural variation in copy number of the ChrY multicopy genes Sycp3 like Y-linked (Sly) and RNA-binding motif, ChrY (Rbmy). ChrY possesses gene regulatory properties that impact both genome-wide gene expression and alternative splicing in a cell type-specific manner depending on the genetic background of the mice. Furthermore, an inverse correlation exists in the number of Sly and Rbmy ChrY multicopy genes and the number of significantly up-regulated genes in immune cells, thereby supporting a link between copy number variation of Sly and Rbmy with the ChrY genetic element exerting regulatory properties. Additionally, by comparing female B6 mice with B6-ChrY consomic lines we show that ChrY polymorphism also determines the gender specificity of the sexual dimorphism in AI disease. Thus, these data support an evolutionarily conserved mechanism retained by mammalian ChrYs to influence complex phenotypes, including susceptibility to AI disease, by acting as a global trans-expression quantitative trait locus (trans-eQTL) in males.

\section{Results}

ChrY consomic strains exhibit a continuous distribution in $\mathrm{Al}$ disease severity characteristic of a quantitative trait

Investigating the genetic components underlying ChrY's ability to regulate susceptibility to $\mathrm{AI}$ disease in male mice is complicated by its structure, which prevents traditional methods of candidate gene identification. However, linkage of disease susceptibility to specific ChrY polymorphisms can be achieved by comparing the strain distribution pattern (SDP) of disease susceptibility with the SDPs for natural genetic variations segregating among ChrYs. This comparison is made possible through the use of ChrY consomic strains of mice, also known as chromosome substitution strains. These mice are generated by intercrossing a male mouse possessing a ChrY of interest to a female mouse with the desired genetic background, which in this study is B6. Then, through a series of backcrosses of 10 generations or more to B6 females, the autosomes, ChrX, the pseudoautosomal (PAR) regions of ChrX and $\mathrm{ChrY}$, and the mitochondrial genome of the strain donating ChrY are replaced with the $\mathrm{B} 6$ genome. Therefore, the genetic variation among ChrY consomic strains presumably comes from the nonrecombining region of $\mathrm{ChrY}$ called the nonpseudoautosomal or male-specific region (Nadeau et al. 2012).

To identify the source of the ChrY polymorphism controlling susceptibility to AI disease, we monitored the severity of both EAE and CVB3-induced myocarditis among a panel of B6-ChrY consomic strains, where the mouse strain donating ChrY to B6 is indicated in superscript (e.g., B6-ChrY $\mathrm{C}^{\mathrm{A} / \mathrm{J}}$ ). To test for susceptibility to EAE, adult male mice from 10 different B6-ChrY consomic strains were immunized with $100 \mu \mathrm{g}$ of myelin oligodendrocyte glycoprotein peptides $35-55$ (MOG $_{35-55}$ ) in complete Freund's adjuvant (CFA) on day 0 and day 7 ( $2 \times$ protocol) and scored for clinical signs of EAE for $30 \mathrm{~d}$ following immunization. Analysis of the severity of the clinical disease course $(P<0.00001)$ (Fig. 1A) and the cumulative disease scores (CDS) (overall $P \leq 0.0009$ ) (Fig. 1B) for B6 and each of the B6-ChrY consomic strains revealed a continuous distribution in disease severity across the strains, consistent with quantitative inheritance (Castle 1914; East 1916). The severity of the clinical disease course for each consomic strain was compared with $\mathrm{B} 6$ identifying $\mathrm{B} 6-\mathrm{ChrY}^{\mathrm{A} / \mathrm{J}}$, $\mathrm{B} 6-\mathrm{ChrY}^{\mathrm{MET}}, \mathrm{B} 6-\mathrm{ChrY}^{\mathrm{PWD}}, \mathrm{B} 6-\mathrm{ChrY}^{\mathrm{ST}}, \mathrm{B} 6-\mathrm{ChrY}^{\mathrm{BUB}}$, and B6$\mathrm{ChrY}^{\mathrm{WSB}}$ as being equivalently susceptible to EAE as B6 (Supplemental Fig. S1A). In contrast, B6-ChrY ${ }^{\mathrm{MA}}, \mathrm{B} 6-\mathrm{ChrY}^{129}, \mathrm{~B} 6-\mathrm{ChrY}^{\mathrm{RF}}$, B6-ChrY ${ }^{\mathrm{LEWES}}$, and $\mathrm{B} 6-\mathrm{ChrY}^{\mathrm{SJL}}$ showed a significant reduction in the severity of the course of clinical disease compared with B6 (Supplemental Fig. S1B). Among these low-responder strains, B6$\mathrm{ChrY}^{\mathrm{SJL}}$ exhibited the largest difference in both clinical disease and neuropathology (Fig. 1C).

Myocarditis is an inflammatory heart disease with an AI component that is often caused by local infections and predominates in both men and male experimental mice (Gauntt and Huber 2003; Fairweather et al. 2013). We recently reported an effect of sex chromosome complement on coxsackievirus B3 (CVB3)induced myocarditis using the "four core genotypes" (FCG) mouse model designed to independently investigate the contribution of sex chromosomes (XX vs. XY) or gonadal type (ovaries vs. testes) on disease (Arnold and Chen 2009). Compared with gonadectomized XX-female and XX-male mice, gonadectomized XY-female and XY-male mice exhibited less severe disease, indicating that myocarditis susceptibility is influenced by ChrX and/or ChrY (Robinson et al. 2011). The response of FCG mice to infection with CVB3 and the development of CVB3-induced myocarditis in XX animals are similar to the response of SJL-FCG mice to EAE, in which the XX sex chromosome complement is associated with significantly more severe disease than the XY complement (SmithBouvier et al. 2008). The interpretation of this outcome favored by these authors is that the increase in EAE severity seen in female SJL mice is primarily a function of the XX complement. However, using SJL-ChrY ${ }^{\mathrm{B} 10 . \mathrm{S}}$ consomic mice, we also show that $\mathrm{ChrY}^{\mathrm{SJL}}$ can influence the difference in EAE susceptibility between female $\left(\mathrm{X}^{\mathrm{SJL}} \mathrm{X}^{\mathrm{SJL}}\right)$ and male $\left(\mathrm{X}^{\mathrm{SJL}} \mathrm{Y}^{\mathrm{SJL}}\right)$ mice (Spach et al. 2009). Therefore, to assess whether susceptibility to myocarditis is similarly regulated by natural polymorphic variation in ChrY, male mice from four B6-ChrY consomic strains were infected i.p. with 50 PFU CVB3, and their hearts were evaluated for inflammation and cardiac virus titers $7 \mathrm{~d}$ after infection. We found that $\mathrm{B} 6-\mathrm{ChrY}^{\mathrm{SJL}}, \mathrm{B} 6-\mathrm{ChrY}^{\mathrm{MA}}$, and $\mathrm{B} 6-\mathrm{ChrY}^{\mathrm{PWD}}$ mice, but not $\mathrm{B} 6-\mathrm{ChrY}^{129}$ mice, exhibit a signif- 
icant decrease in CVB3-induced myocarditis relative to B6 (Fig. 1D). Residual heart virus titers did not predict the heart score among the strains with the exception of $\mathrm{B} 6-\mathrm{ChrY}^{\mathrm{PWD}}$, which had both significantly lower viral titers $(P \leq 0.05)$ as well as lower myocarditis scores $(P \leq 0.001)$ compared with B6 (Fig. 1D,E and data not shown). Taken together, two diverse models of AI disease exhibit a continuous distribution in disease severity across the B6-ChrY consomic strains, which is characteristic of quantitative inheritance.
Sry expression level polymorphisms and variation in testosterone production do not correlate with EAE severity

Previously, we showed that neither the serum testosterone levels nor the survival of CVB3-infected B6-ChrY male mice were controlled by Sry expression level polymorphisms (Case et al. 2012), which when inherited by $\mathrm{B} 6$ mice heterozygous for the t-complex encoded TOrleans mutation on Chr17, leads to varying degrees of sex reversal (Nagamine et al. 1999; Washburn et al. 2001; Albrecht et al. 2003). Similarly, by comparing the EAE-CDS for B6 and each consomic strain with their serum testosterone levels, we found that EAE severity also does not correlate with differences in testosterone production $(r=0.36 ; P=$ 0.27 ), a hormone that is known to influence EAE and myocarditis severity in males (Fig. 1F; Huber et al. 1982; Lyden et al. 1987; Bebo et al. 1998; Fillmore et al. 2004; Frisancho-Kiss et al. 2009; Spence and Voskuhl 2012).

To examine whether Sry expression level polymorphisms affect susceptibility to AI disease, we compared the SDP of Sry alleles with EAE-CDS across the B6-ChrY consomic strains. This revealed that Sry polymorphisms similarly do not influence disease severity, suggesting that Sry expression polymorphisms do not underlie the differences in disease phenotypes $(P=0.165)$ (Fig. 1G). Furthermore, as previously reported, we found that Sry polymorphisms do not influence the level of adult testosterone production in the B6ChrY consomic strains $(P=0.354)$ (Case et al. 2012). Additionally, an analysis of the single nucleotide polymorphism (SNP) variation using the Mouse Phenome Database identified only two ChrY haplogroups among the strains with limited diversity that are also discordant with disease susceptibility (Supplemental Table S2). Given the limited SNP diversity between the annotated regions on the short arm of ChrYs, it is important to consider the impact that other polymorphisms, such as structural polymorphism, may have on regulating phenotypes.

\section{ChrY gene copy number variation} correlates with EAE and myocarditis severity among the B6-ChrY consomic strains

Structural polymorphism can arise through variations in the number of repeat sequences, inverted sequences, and retroelements present in ChrY DNA. In Drosophila, ChrY-mediated phenotypic differences are attributed to natural polymorphic variation in multicopy ribosomal genes present on ChrY (Lemos et al. 2008, 2010; Paredes et al. 2011; Zhou et al. 2012). The musculus ChrY possesses several

Figure 1. (Legend on next page) 
multicopy genes, including Sly, Rbmy, and spermiogenesis transcript on the Y 1 (Ssty1), that differ in number between ChrYs of inbred strains (Fig. 2A). Therefore, to investigate whether copy number variation in these multicopy ChrY genes may impact susceptibility to EAE, we ran a correlation analysis between gene copy number and CDS. This analysis shows that the number of gene copies of Sly and Rbmy, but not Ssty1, correlates with the severity of EAE (Fig. 2B). Similarly, a correlation analysis between gene copy number and myocarditis heart score also reveals a striking association between the number of gene copies of Sly and Rbmy, but not Ssty1, with the severity of CVB3-induced myocarditis (Fig. 2C).

\section{The mammalian ChrY acts as a trans-eQTL shaping immune cell transcriptomes}

Given that the ChrY-mediated influence on AI disease susceptibility is indicative of a quantitative trait, we sought to determine whether ChrY can act as trans-eQTL and regulate global gene expression in cells central to disease pathogenesis (Bhasin et al. 2008). We analyzed the transcriptome of naive $\mathrm{CD} 4^{+} \mathrm{T}$ cells, which are essential to disease pathogenesis in $\mathrm{B} 6$ mice, between resistant B6-ChrY ${ }^{\mathrm{SJL}}$ and susceptible B6 male mice by microarray analysis. RNA was isolated from fluorescently activated cell sorted (FACS) $\mathrm{CD} 4{ }^{+} \mathrm{TCR}^{+}$cells obtained from the lymph nodes of adult ( $8 \mathrm{wk}$ of age) naïve $\mathrm{B} 6-\mathrm{ChrY} \mathrm{YSL}^{\mathrm{SL}}$ and $\mathrm{B} 6$ male mice, and mRNA expression, the presence of alternative splice variants, and miRNA expression were assessed in each sample.

After filtering the gene array data using a false discovery rate (FDR) $<0.05$, we identified 734 differentially expressed transcripts between B6-ChrY ${ }^{\mathrm{SLL}}$ and B6 CD4 ${ }^{+}$T cells. Furthermore, 3247 transcripts were identified as being alternatively spliced, with 398 of these being both alternatively spliced and differentially expressed (Fig. 3A). These differentially regulated genes are distributed throughout the genome and reside on all autosomes and both sex chromosomes. Interestingly, no miRNA probe sets passed an FDR of 0.05. These data demonstrate the magnitude of ChrY's ability to act as a trans-eQTL and epigenetically regulate the transcriptome, particularly in relation to alternative splicing, and raise the possi- bility that gene regulation may be independent of miRNA expression in $\mathrm{CD}^{+} \mathrm{T}$ cells.

\section{Differential expression of chromatin remodeling genes in B6-ChrYSJL vs. B6 CD4 ${ }^{+} \mathrm{T}$ cells}

We utilized the Mouse Genome Informatics (MGI) Gene Ontology (GO) Term Finder to identify the GO terms containing a significant enrichment of genes within the $\mathrm{B} 6-\mathrm{ChrY}^{\mathrm{SJL}}$ vs. B6 alternatively spliced and differentially expressed transcript lists (Fig. 3A; Supplemental Tables S3, S4). Both lists contained multiple terms associated with chromatin dynamics whose dysregulation has the potential to lead to the ChrY-dependent genome-wide transcriptome differences observed in $\mathrm{CD}^{+} \mathrm{T}$ cells. Therefore, to confirm these gene associations, we used a quantitative PCR (qPCR) array specific for mouse epigenetic chromatin remodeling factors to assess their differential expression in $\mathrm{B} 6-\mathrm{ChrY}^{\mathrm{SJL}}$ vs. $\mathrm{B} 6 \mathrm{CD}^{+} \mathrm{T}$ cells. Of the 84 chromatin remodeling genes represented on the qPCR array, 54 exhibited significant differences in gene expression between $\mathrm{B} 6-\mathrm{ChrY}^{\mathrm{SJL}}$ and $\mathrm{B} 6 \mathrm{CD}^{+}{ }^{+} \mathrm{T}$ cells, consistent with $\mathrm{ChrY-}$ mediated changes in chromatin remodeling gene expression identified in the microarray (Fig. 3B; Supplemental Table S5).

\section{ChrY-mediated transcriptome differences translate to alterations in cytokine production in stimulated $\mathrm{CD}^{+} \mathrm{T}$ cells}

We used Ingenuity Pathway Analysis (IPA) to identify specific canonical pathways that might be affected by the ChrY-dependent changes in the $\mathrm{CD} 4^{+} \mathrm{T}$-cell transcriptome. We included the genes from both the alternatively spliced and differentially expressed lists and used the core analysis feature of IPA. The top 10 canonical pathways identified by IPA include those involved in gene expression, protein synthesis, T- and B-cell signaling, and glucocorticoid receptor signaling, consistent with the MGI GO term data (Supplemental Fig. S3). Furthermore, three of the pathways were specific for signaling in T cells, including T-cell receptor signaling, leading us to hypothesize that the activation profile should markedly differ between $\mathrm{B} 6-\mathrm{ChrY}^{\mathrm{SJL}}$ and $\mathrm{B} 6 \mathrm{CD}^{+}{ }^{\mathrm{T}}$ cells (Fig. 3C).

To address this, purified $\mathrm{CD} 4^{+} \mathrm{T}$ cells from $\mathrm{B} 6-\mathrm{ChrY}^{\mathrm{SJL}}$ and $\mathrm{B} 6 \mathrm{lymph}$ nodes were stimulated with anti-CD3 and anti-CD28

Figure 1. Natural genetic variation in ChrY mediates susceptibility to autoimmune disease. $(A)$ Male mice from the $\mathrm{B} 6-\mathrm{ChrY}$ consomic strains were immunized with $\mathrm{MOG}_{35-55}$ using the $2 \times$ protocol and the clinical score was monitored over $30 \mathrm{~d}$. The consomic strain represented by each line is color-coded with the bar graph in B. Wild-type B6 male are represented by black circles. The significance of the differences in disease course among the strains was determined by two-way ANOVA (interaction [ $F=$ $1.18 ; \mathrm{DFn}=319 ; \mathrm{DFd}=7770 ; P=0.02]$, day post-injection $[F=132.81 ; \mathrm{DFn}=29 ; \mathrm{DFd}=7770 ; P<$ $0.0001]$, and strain $[F=23.53 ; \mathrm{DFn}=11 ; \mathrm{DFd}=7770 ; P<0.0001])$. (B) The degree of EAE susceptibility among the B6-ChrY consomic mice was calculated by subtracting the clinical disease score (CDS) of B6 from the CDS of each strain. The $x$-axis indicates the strain origin of the $Y$ chromosome. $F=2.58, P \leq$ 0.0009 . A heterogeneity test was used between cohorts of mice with no significant differences detected. Thus, data were pooled from three independent experiments and the total number of animals analyzed in $A$ and $B$ are indicated in Supplemental Table S1. (C) Immunohistopathology of the brain and spinal cord from B6-ChrY consomic strains immunized using the $2 \times$ protocol. Only the total histopathology score is shown. Significance determined by one-way ANOVA. $\left({ }^{\star *}\right) P \leq 0.01$. (D) Male mice from wildtype B6 and four consomic lines were infected with 50 PFU CVB3 and their hearts were evaluated for myocarditis. Heart score of B6 was subtracted from the heart score for each consomic. Labeling on the $x$-axis represents the strain donating ChrY to B6. Results are representative of three individual experiments. $n \geq 5$ mice per strain. Significance determined by one-way ANOVA and Dunnett's multiple comparison test. $\left({ }^{*}\right) P \leq 0.05 ;\left({ }^{* *}\right) P \leq 0.01 ;\left(^{* * *}\right) P \leq 0.001$. (E) Linear regression analysis of heart score and heart viral titers reveals the absence of a significant relationship between the regressed variables. Left $x$-axis (orange linear regression line and orange circles) corresponds to the B6-ChrY consomic data combined from each of the four tested strains. $F=0.72, P=0.41$. Right $x$-axis (black linear regression line and black squares) corresponds to the WT B6 data. $F=0.43, P=0.52$. (F) Correlation analysis of serum testosterone with the CDS for $\operatorname{EAE}(r=0.36 ; P=0.27)$. (G) Functionally significant Sry polymorphisms are discordant with ChrY-mediated differences in disease susceptibility. Data from $B$ were grouped according to their functional Sry polymorphisms. monoclonal antibodies and the supernatants were tested for IL2, IFNG, IL17A, TNF, and IL6 production after 24,48 , and $72 \mathrm{~h}$ by ELISA. We observed significant reductions in IFNG, IL17A, and IL6 cytokine secretion by stimulated $\mathrm{CD}^{+}$ $\mathrm{T}$ cells from $\mathrm{B} 6-\mathrm{ChrY}^{\mathrm{SJL}}$ compared with B6 (Fig. 3D). These data indicate that the ChrY-mediated changes in the $\mathrm{CD} 4^{+} \mathrm{T}$-cell transcriptome, as identified by microarray analyses, translates directly into altered protein synthesis as a result of biological changes in T-cell activation and signaling.

\section{ChrY exerts cell type-specific effects on gene regulation depending on the autosomal background of the mice}

Unlike the B6 strain, SJL mice exhibit a sexual dimorphism in EAE that is the result of an age-dependent resistance in 


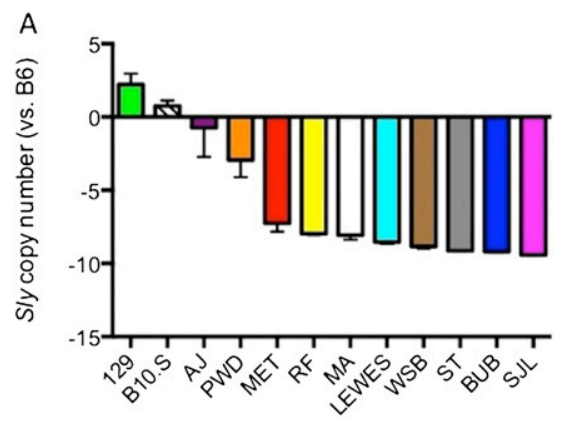

B
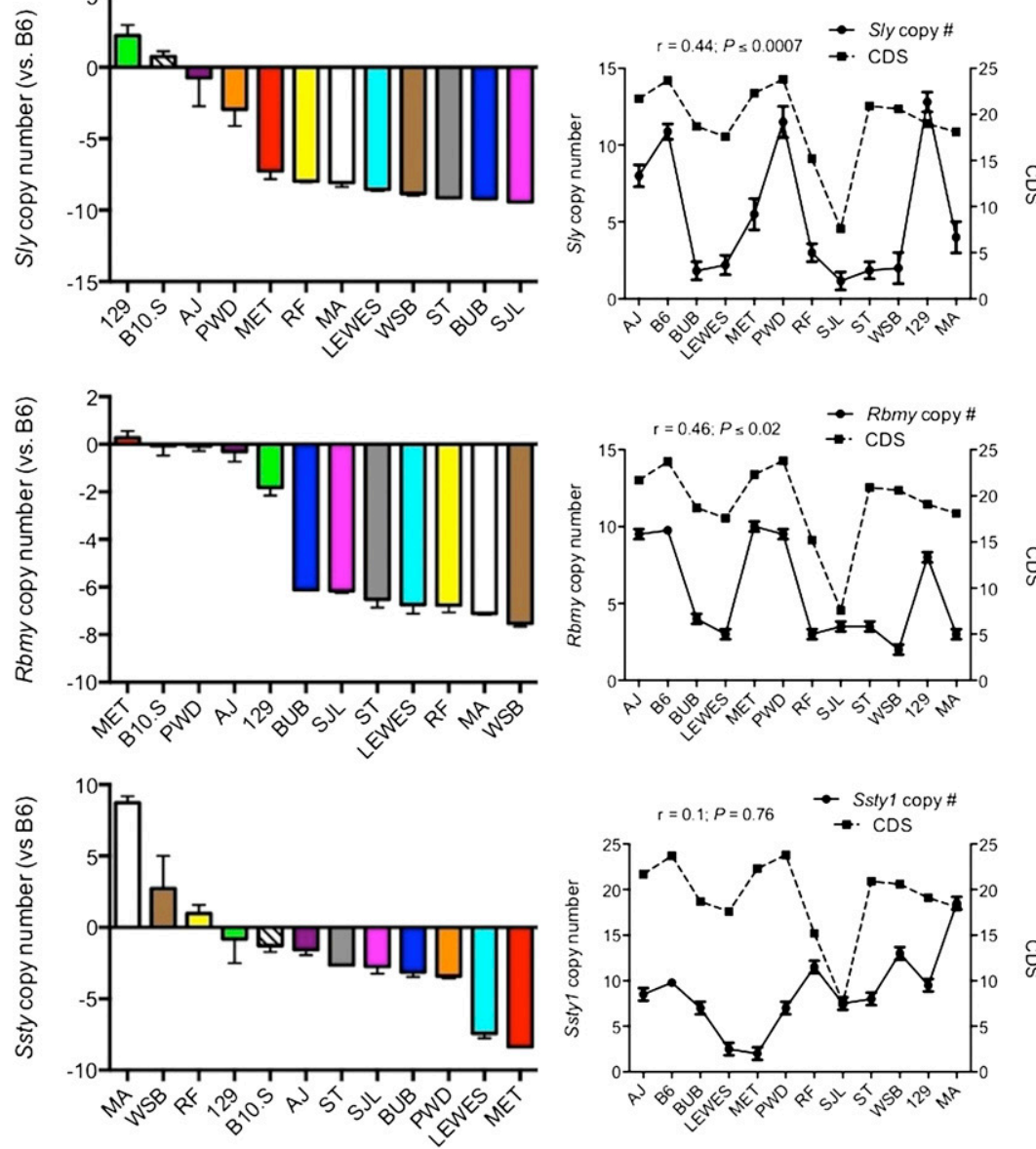
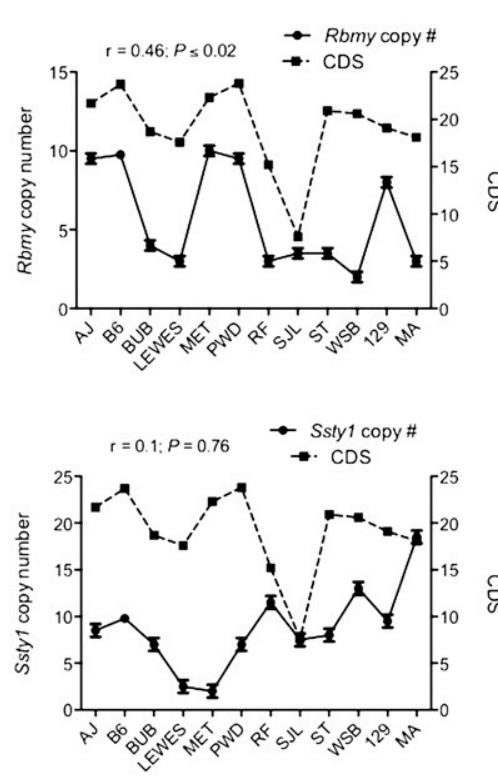

C
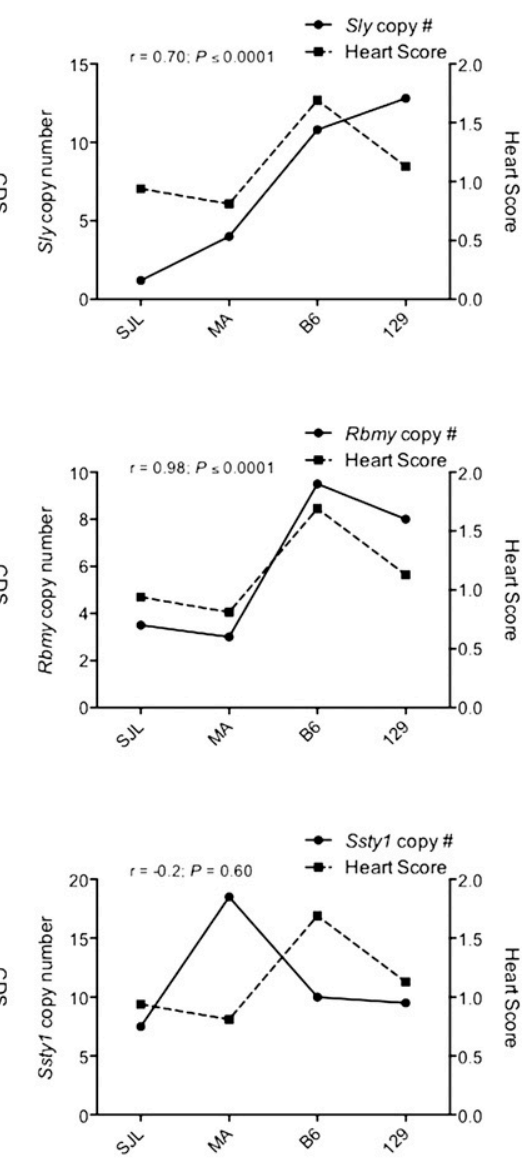

Figure 2. Sly and Rbmy gene copy number correlates with EAE and CVB3 susceptibility among B6-ChrY consomic strains. (A) Gene copy number for each of the consomic strains relative to B6. $n \geq 5$ mice per strain. (B) Correlation analysis of gene copy number with the CDS for EAE. (C) Correlation analysis of gene copy number with myocarditis heart score. The $x$-axis represents the strain origin of ChrY.

males due, in part, to the inability of macrophages from young SJL mice to efficiently process and present antigen to effector cells (Stohlman et al. 1985; Cua et al. 1995; Papenfuss et al. 2004). Furthermore, this phenotype is reliant on the $\mathrm{ChrY}^{\mathrm{SJL}}$, because young SJL male mice inheriting $\mathrm{ChrY}^{\mathrm{B} 10 . \mathrm{S}}$ (SJL-ChrY ${ }^{\mathrm{B} 10 . \mathrm{S}}$ ) are as susceptible to disease as older males (Spach et al. 2009). To test whether ChrY acts as a trans-eQTL in the immune cells essential to disease susceptibility in SJL mice, we analyzed the transcriptomes of FACS-purified CD4 ${ }^{+} \mathrm{T}$ cells and adherent macrophages from young ( $\leq 4 \mathrm{wk}$ of age) and old ( $\geq 6$ mo of age) male SJL-ChrY ${ }^{\mathrm{B} 10 . \mathrm{S}}$ and SJL mice. An analysis of the main effect of strain on each of the cell types suggest that ChrY has a greater influence on the transcriptome of macrophages compared with $\mathrm{CD} 4^{+} \mathrm{T}$ cells, with 2932 vs. 42 differentially expressed transcripts passing an FDR < 0.05 , respectively (Fig. 4A,B).

Similar to the B6-ChrY consomic comparison, ChrY also greatly influences the alternative splicing of genes in the SJL$\mathrm{ChrY}^{\mathrm{B} 10 . \mathrm{S}}$ and SJL strain combination, with 2987 vs. 348 alternatively spliced transcripts in macrophages and $\mathrm{CD}^{+} \mathrm{T}$ cells, respectively (Fig. 4A,B). MGI GO term analysis on the CD $4^{+}$T-cell data set indicated that the alternatively spliced transcripts contained significant term associations for transcriptome regulation whereas no significant term enrichments were identified for the differentially expressed transcript list (Fig. 4A; Supplemental Table S6). Interestingly, the genes represented in the macrophage array have very different signatures depending on whether they are alternatively spliced or differentially expressed. Alternatively spliced genes typically function in regulating gene expression, as was observed for $\mathrm{CD}^{+}{ }^{+} \mathrm{T}$ cells, whereas the differentially expressed genes function in other diverse cellular processes unrelated to gene regulation (Fig. 4B; Supplemental Tables S7, S8). These data reveal that allelic differences in ChrY affects gene regulation more in macrophages than $\mathrm{CD}^{+}{ }^{+} \mathrm{T}$ cells in the SJL genetic background. Thus, these data provide further support for the existence of gene regulatory elements within ChrY that exert regulatory properties and show that these effects are cell-typeand autosomal background-dependent.

The number of Sly and Rbmy gene copies is inversely correlated with the up-regulation of gene expression

The microarray analyses described above led to a striking observation in the directionality of transcript expression within both ChrY consomic backgrounds. In $\mathrm{B} 6-\mathrm{ChrY}^{\mathrm{SJL}} \mathrm{CD}^{+}{ }^{\mathrm{T}}$ cells, $>75 \%$ of the differentially expressed transcripts were preferentially up-regulated compared with wild-type B6. In contrast, placing $\mathrm{ChrY}^{\mathrm{B} 10.5}$ on the 
A
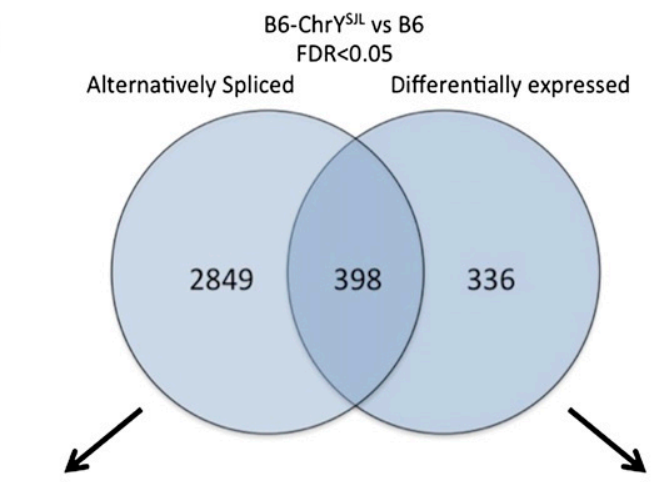

Metabolic Process Gene Expression Regulation of Signaling Chromosome Organization Immune System Process

B

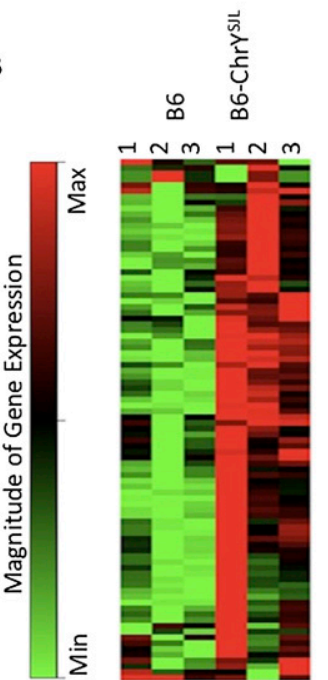

IL-17
Metabolic Process Gene Expression Immune System Process Chromosome Organization c

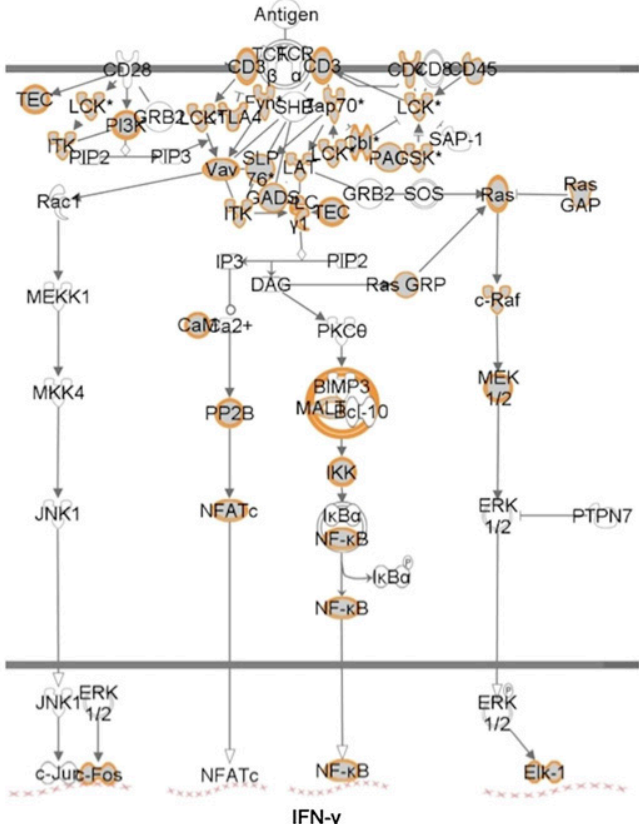

$\mathrm{IL}-2$
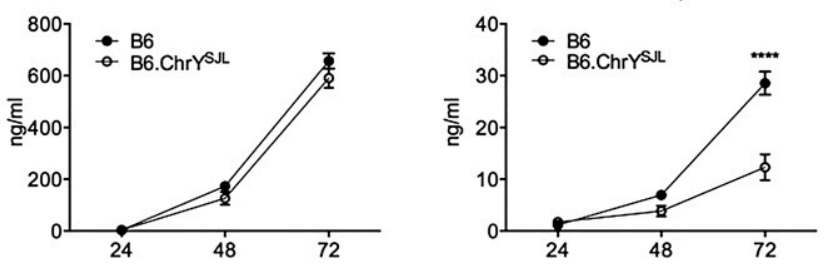

IL-6
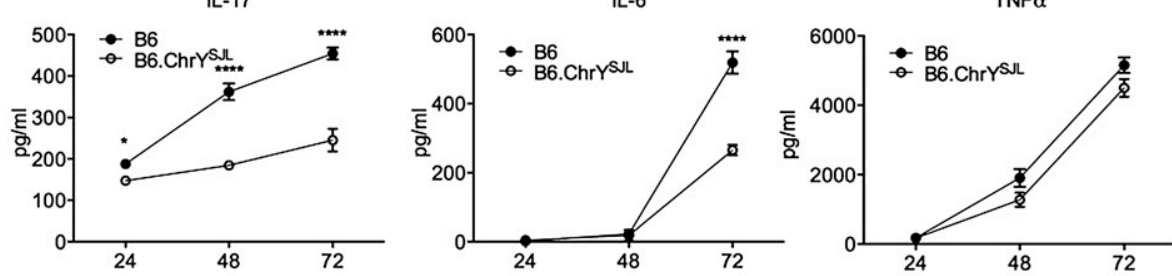

Figure 3. ChrY-mediated regulatory variation in genome-wide gene expression influences the activation profile of CD4 ${ }^{+} \mathrm{T}$ cells. $(A)$ Venn diagram representing the number of genes passing an FDR $<0.05$ between $B 6-C h r Y^{S J L}$ and $B 6 C D^{+}{ }^{+} T$ cells. MGI GO Term Finder was used to identify enriched biological processes associated with each gene list, examples of which are shown. (B) Heat map from quantitative PCR array specific for mouse epigenetic chromatin remodeling factors on three biological replicates of purified $\mathrm{CD} 4^{+} \mathrm{T}$ cells from $\mathrm{B} 6$ and $\mathrm{B} 6-\mathrm{ChrY} \mathrm{SLL}^{\mathrm{IL}}$. Red represents up-regulated genes and green down-regulated genes. Degree of change indicated by intensity of color. (C) IPA TCR signaling pathway with the molecules differentially regulated between B6-ChrY ${ }^{\mathrm{SL} L}$ and $\mathrm{B} 6 \mathrm{CD} 4^{+} \mathrm{T}$ cells highlighted in orange. $(D)$ Purified $\mathrm{CD} 4^{+} \mathrm{T}$ cells from B6-ChrY ${ }^{\mathrm{SL} L}$ and $\mathrm{B} 6$ lymph nodes were incubated with antiCD3 and anti-CD28 monoclonal antibodies and the supernatants were tested for IL2, IFNG, IL17A, TNF, and IL6 production after 24, 48 , and $72 \mathrm{~h}$ by ELISA. Data are representative of three independent experiments. Significance determined by two-way ANOVA followed by Bonferroni post-hoc multiple comparison test. $\left({ }^{*}\right) P \leq 0.05 ;(* * *) P \leq 0.0001$.

SJL background resulted in the down-regulation of $>85 \%$ of the differentially expressed transcripts in $\mathrm{CD}^{+}{ }^{+} \mathrm{T}$ cells and $\sim 60 \%$ of the differentially expressed transcripts in macrophages compared with the wild-type $\mathrm{ChrY}^{\mathrm{SJL}}$. Therefore, $\mathrm{ChrY}^{\mathrm{SJL}}$ contains an overall low number of multicopy genes and an increase in the number of up-regulated genes. Conversely, $\mathrm{ChrY}^{\mathrm{B} 10 . \mathrm{S}}$ contains a high number of multicopy genes, which is equivalent to that of $\mathrm{ChrY}^{\mathrm{B} 6}$, and a decrease in the number of up-regulated genes (Fig. 4C). These data indicate that an inverse correlation exists between Sly and Rbmy copy number variation and the up-regulation of gene expression in immune cells, thereby providing a link between the copy number variation of Sly and Rbmy with the ChrY trans-eQTL regulatory properties.

\section{Evidence for the evolutionary conservation of ChrY as an eQTL in MS susceptibility}

A recent study focusing on coronary artery disease in humans revealed a link between disease susceptibility and ChrY haplogroups in association with distinct autosomal and ChrX transcriptional profiles in macrophages (Charchar et al. 2012). This work indicates that, like in Drosophila and mice, ChrY polymorphism may influence disease susceptibility by regulating the gene expression profiles of pathogenic immune cells in men. Therefore, to identify pathways known to be directly regulated by ChrY polymorphism in mice and that are evolutionarily conserved in humans, we utilized a naïve $\mathrm{CD} 4^{+} \mathrm{T}$-cell expression data set from male MS patients 
A

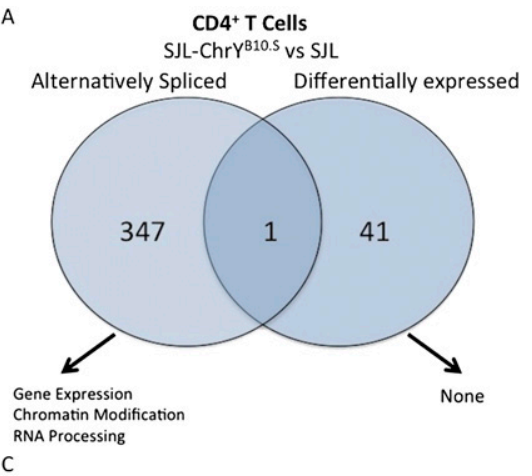

C

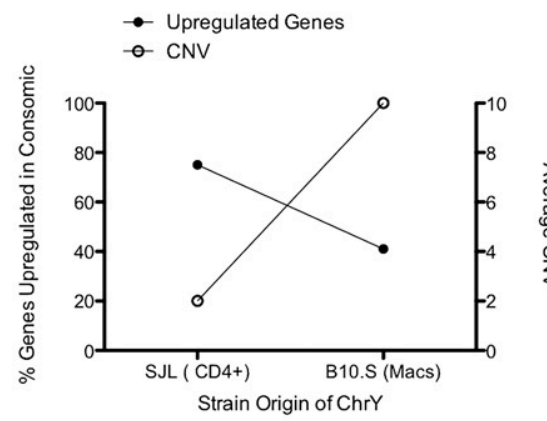

Figure 4. ChrY preferentially regulates the transcriptome of macrophages compared with $C D 4^{+} T$ cells in the SJL genetic background. Venn diagram representing the number of genes passing an FDR < 0.05 between SJL-ChrY ${ }^{B 10.5}$ and SJL. $(A) C^{C D} 4^{+} T$ cells and $(B)$ macrophages. MGI GO Term Finder was used to identify enriched biological processes associated with each gene list, examples of which are shown. (C) Graph representing the percentage of up-regulated genes in the ChrY consomic strain vs. the parental in relation to the averaged copy number variation for Sly and Rbmy. (D) A Venn diagram representing the genes differentially regulated between the human and $\mathrm{B} 6$ mouse $\mathrm{CD} 4^{+} \mathrm{T}$-cell microarrays, 440 of which are shared between the two species. MGI GO term analysis on these shared terms identified an enrichment of genes involved in gene regulatory processes.
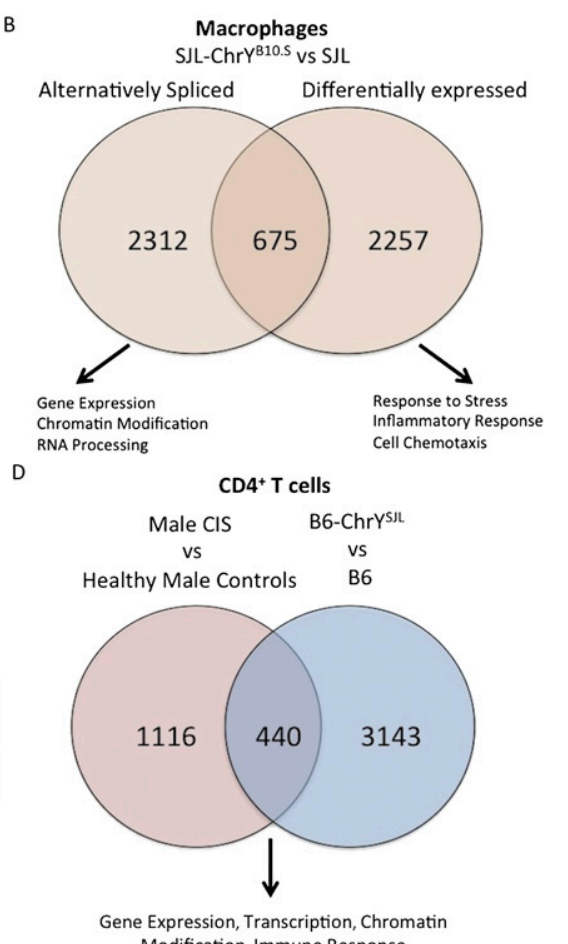

Expression, Transcription, Chromatin sex chromosome complement (Robinson et al. 2011). In contrast, B6 mice do not typically exhibit a sexual dimorphism in EAE (Papenfuss et al. 2004), which is consistent with the lack of a sex chromosome complement effect observed in the B6-FCG model (Smith-Bouvier et al. 2008).

Interestingly, by comparing the myocarditis heart scores of B6-ChrY consomic strains with the heart score of female B6 mice, the sexual dimorphism is eliminated by $\mathrm{ChrY}^{\mathrm{PWD}}$ (Fig. 5A). Furthermore, by comparing the EAE clinical disease course of B6-ChrY consomic strains with the disease course of female B6 mice, we find that varying degrees of sexual dimorphism in EAE severity emerge in this otherwise non-sexually dimorphic strain (Fig. 5B,C). No sexual dimorphism in EAE severity was observed between $\mathrm{B} 6$ females and male $\mathrm{B} 6, \mathrm{~B} 6-\mathrm{ChY}^{\mathrm{A} / \mathrm{J}}, \mathrm{B} 6-$ $\mathrm{ChrY}^{\mathrm{BUB}}, \mathrm{B} 6-\mathrm{ChrY}^{\mathrm{MET}}, \mathrm{B} 6-\mathrm{ChrY}^{\mathrm{ST}}$, or B6$\mathrm{ChrY}^{\mathrm{WSB}}$ consomic mice. In contrast, compared with $\mathrm{B} 6$ females, B6-ChrY $\mathrm{YWD}^{\mathrm{PWD}}$ males exhibited increased disease severity while male B6-ChrY ${ }^{\mathrm{LEWES}}$, B6-ChrY ${ }^{\mathrm{MA}}$, B6-ChrY ${ }^{\mathrm{RF}}, \mathrm{B} 6-\mathrm{ChrY}^{\mathrm{SJL}}$, and $\mathrm{B} 6-\mathrm{ChrY}^{129}$ consomic mice presented with less severe disease (Fig. 5C). Clearly, the inheritance of polymorphic ChrYs has a profound effect on disease susceptibility in B6 males and may play an important role in determining the gender bias observed in the AI diseases studied. exhibiting the earliest clinical signs of disease, known as clinically isolated syndrome (CIS), with healthy controls available through the Gene Expression Omnibus (Series GSE13732) (Corvol et al. 2008). After filtering the data set using a FDR $<0.05$, we identified 1556 differentially expressed genes between male CIS and controls. Overlapping this filtered data set with the $\mathrm{B} 6-\mathrm{ChrY}^{\mathrm{SJL}}$ vs. B6 mouse $\mathrm{CD} 4^{+}$T-cell data set identified 440 genes common between mouse and human. This list was specifically enriched for genes functioning in gene expression $\left(P=3.8 \times 10^{-34}\right)$, transcription $(P=$ $\left.6.62 \times 10^{-20}\right)$, chromatin modification $\left(P=4.02 \times 10^{-12}\right)$, and immune system processes $\left(P=2.07 \times 10^{-11}\right)$ (Fig. 4D; Supplemental Table S9). Therefore, this analysis provides preliminary evidence for the evolutionary conservation of ChrY as an eQTL capable of modifying the regulatory genome of $\mathrm{CD} 4^{+} \mathrm{T}$ cells and MS susceptibility in men.

\section{Genetic variation in ChrY modifies the sexual dimorphism in myocarditis and leads to a sex bias in EAE severity}

Autoimmune diseases often exhibit a sexual dimorphism in their incidence, clinical course, and/or severity (McCombe et al. 2009). MS predominates in women by a 3:1 ratio, whereas myocarditis predominates in men by a 2:1 ratio, and in both AI diseases, men often develop more severe disease compared with females. Similarly, CVB3-induced myocarditis is more severe in male B6 mice than in females, and this sexual dimorphism is influenced by the

\section{Discussion}

It is well established that ChrY protein-coding genes are critical for the sexual development and fertility of males. Beyond this, however, there is only a small, though growing, body of research exploring the existence of alternative functions for ChrY in determining organismal phenotypes (Monahan and Maxson 1998; Burgoyne et al. 2002; Wesley et al. 2007; Spach et al. 2009; Arnold 2012; Case et al. 2012; Charchar et al. 2012; Chen et al. 2013). Here we show that natural polymorphic variation in ChrY impacts susceptibility to two diverse animal models of AI disease by acting as a trans-eQTL in immune cells linked to disease pathogenesis. The genome-wide regulatory properties of ChrY, which impact both gene expression and alternative splicing, establish this chromosome as a member of the regulatory genome in males. Importantly, an inverse correlation exists between the copy number variation in Sly and Rmby ChrY multicopy genes and the number of significantly up-regulated genes in immune cells, thereby providing a link between copy number variation and the ChrY genetic element exerting regulatory properties.

Studies on the Drosophila ChrY were the first to reveal its global gene regulatory properties and these studies have guided our investigation into whether a related mechanism was evolutionarily conserved by the mammalian ChrY. Research suggests that, in Drosophila, ChrY plays an important role in regulating the heterochromatic state of autosomal and ChrX chromatin, thereby

\section{Genome Research www.genome.org}


A

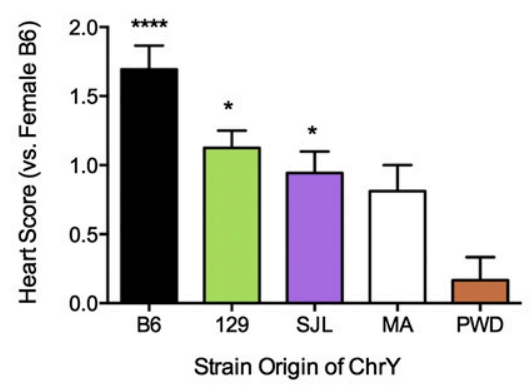

B

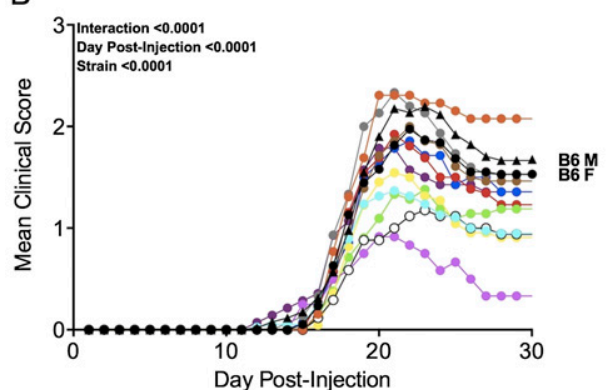

C

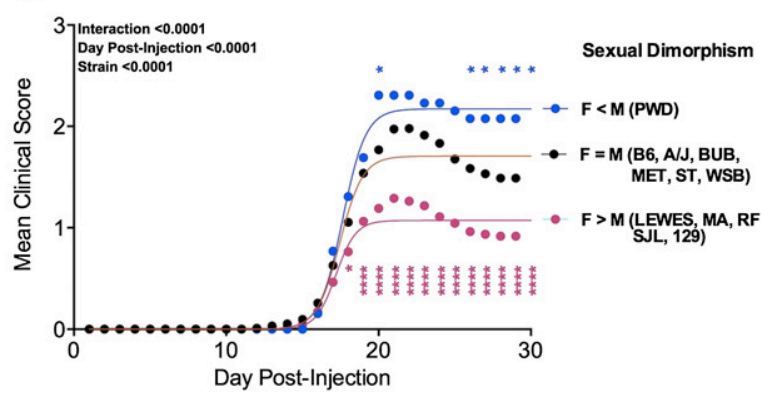

Figure 5. Genetic variation in ChrY modifies the sexual dimorphism in myocarditis and leads to a sex bias in EAE severity. (A) Male and female mice from WT B6 and male mice from four B6-ChrY consomic strains were infected with 50 PFU CVB3 and their hearts were evaluated for myocarditis. Heart score of female B6 was subtracted from the heart score for male WT B6 and each B6-ChrY consomic strain. Labeling on the $x$-axis represents the strain donating $\mathrm{ChrY}$ to B6. Results are representative of three individual experiments. $n \geq 5$ mice per strain. Significance determined by one-way ANOVA and Dunnett's multiple comparison test. $\left(^{*}\right) P \leq 0.05$; $\left({ }^{* * * *}\right) P \leq$ 0.0001 . (B) Female B6 and male B6-ChrY consomic mice were immunized with $\mathrm{MOG}_{35-55}$ using the $2 \times$ protocol and the clinical score was monitored over $30 \mathrm{~d}$. The significance of the differences in disease course among the strains was determined by two-way ANOVA (interaction $[F=1.18$; DFn $=319$; $\mathrm{DFd}=7770 ; P=0.02]$, day post-injection $[F=132.8 ; \mathrm{DFn}=29 ; \mathrm{DFd}=7770$; $P<0.0001]$, and strain $[F=23.5 ; \mathrm{DFn}=11 ; \mathrm{DFd}=7770 ; P<0.0001])$. (C) The significance of the differences in disease course between B6 female mice and each B6-ChrY consomic line was determined as described in Supplemental Figure S2 and grouped accordingly. The significance of the differences in sexual dimorphism among the groups was determined by comparing the best-fit values for the $\mathrm{F}<\mathrm{M}$ and $\mathrm{F}>\mathrm{M}$ grouping against the $\mathrm{F}=\mathrm{M}$ group and by two-way ANOVA (interaction $[F=1.14 ; \mathrm{DFn}=348 ; \mathrm{DFd}=8880 ; P=0.04]$, day post-injection $[F=155.5 ; \mathrm{DFn}=29 ; \mathrm{DFd}=8880 ; P<0.0001]$, and strain $[F=22.58 ; \mathrm{DFn}=12 ; \mathrm{DFd}=8880 ; P<0.0001])$ followed by Holm-Sidak corrected post-hoc multiple comparisons. $\left(^{*}\right) P \leq 0.05 ;\left(^{* * *}\right) P \leq 0.0001$.

regulating gene expression and phenotypic differences among males (Piergentili 2010). The degree of ChrY-linked regulatory variation inversely correlates with the number of ribosomal DNA
(rDNA) units within the ChrY rDNA locus, which is a tandemly repeated array consisting of hundreds of units that comprise $\sim 10 \%$ on the entire ChrY (Paredes et al. 2011; Zhou et al. 2012).

In the murine $\mathrm{ChrY},>95 \%$ of the male-specific region is composed of hundreds of units of a tandemly repeated array (Alfoldi 2008). Each unit contains several gene copies from three testis-specific gene families, including Sly, Ssty, and serine-rich, secreted, Y-linked (Srsy) multicopy genes. The remaining 5\% of the male-specific region is similar in structure and composition to the human ChrY and contains several single copy protein-coding genes, such as Sry, as well as another tandemly repeating array with dozens of units, with each unit containing a copy of the proteincoding gene Rbmy (Alfoldi 2008). While the function of Srsy and Ssty remains unknown, Sly represses the post-meiotic expression of ChrX and ChrY genes by maintaining repressive epigenetic marks in sex chromatin (Cocquet et al. 2009; Reynard et al. 2009; Ellis et al. 2011; Cocquet et al. 2012). Furthermore, Sly underlies the ChrY deletion mutation phenotypes in mice that exhibit a range of deficiencies in spermatogenesis depending on the extent of the deletion (Reynard et al. 2009). Rbmy is also important during spermatogenesis and encodes an RNA-binding protein that regulates mRNA splicing, and loss of RBMY expression may contribute to sperm abnormalities in mice and humans (Elliott et al. 2000; Szot et al. 2003; Skrisovska et al. 2007; Zeng et al. 2008; NavarroCosta et al. 2010).

We observed a highly significant correlation between the extent of copy number variation in Sly and Rbmy, but not Ssty1, with disease susceptibility. In addition, similar to the relationship between ChrY-linked regulatory variation with rDNA repeats in Drosophila, copy number variation in Sly and Rbmy is inversely correlated with the up-regulation of genes in immune cells. The regulatory properties of these ChrY multicopy genes are not likely exerted through their protein products since mRNA expression is testis and germ line specific (Elliott et al. 1996; Toure et al. 2005). However, we find our data to be consistent with a mechanism of chromatin remodeling as proposed for the Drosophila ChrY, whereby the multicopy genes may sequester proteins involved in chromatin dynamics (Dimitri and Pisano 1989; Lemos et al. 2008, 2010). Therefore, a high frequency of the ChrY multicopy genes, as seen in $\mathrm{ChrY}^{\mathrm{B} 6}$ and $\mathrm{ChrY}^{\mathrm{B} 10 . \mathrm{S}}$, may lead to the reduced availability of chromatin remodeling proteins, resulting in fewer euchromatic DNA regions and less transcriptional activity. Conversely, since $\mathrm{ChrY}^{\mathrm{SJL}}$ possesses fewer copies of these multicopy genes, more chromatin remodeling proteins are freely available to exert their functions on chromatin, leading to more euchromatic regions and an increase in transcriptional activity. Furthermore, support for a mammalian ChrY-mediated chromatin modification mechanism stems from the surprisingly high number of alternative splice variants identified between the parental and ChrY consomic strains. Recent studies have identified a role for chromatin in the regulation of alternative splicing such that nucleosome positioning along exons, plus the enrichment of chromatin-modifying proteins with splicing factor-binding capabilities, may regulate the recruitment of splicing factors to the pre-mRNA (Luco et al. 2011). Therefore, this study indicates that ChrY is a member of the regulatory genome in males and supports an evolutionarily conserved mechanism of gene regulation by ChrY in the immune cells linked to AI disease. Whether this is a direct consequence of copy number variation in these genes, or whether copy number variation is linked to other genetic features within ChrY, remains unknown. Consistent with our model, ChrY was recently linked to an NK and B-cell deficiency in mice, which is not due to changes in 
protein-coding sequences as determined by exome sequencing, or due to expression differences in $\mathrm{ChrY}$ genes as determined by microarray and qPCR, but is rather due to a structural mutation arising from the deletion of one-third of the entire ChrY (Sun et al. 2013). Therefore, this new study supports the structure of ChrY's long arm as the genetic element exerting gene regulatory properties in immune cells.

Nevertheless, additional studies must be conducted to effectively rule out the existence of genetic variation within the pseudoautosomal region (PAR), an $\sim 700-\mathrm{kb}$ segment at the telomeric end of ChrY (Perry et al. 2001), that could also potentially influence AI disease susceptibility in the ChrY consomic strains. In Mus musculus and Mus domesticus subspecies, the PAR contains one protein-coding gene, called steroid sulfatase (Sts), and the 3 ' end of the midline 1 gene (Mid1), which is non-protein coding and spans the PAR boundary (White et al. 2012). Since the PAR is free to recombine with ChrX and exchange genetic information during male meiosis, all the ChrY consomic strains used in this study presumably possess the B6 PAR. However, the PAR boundary can regularly shift by several hundred kilobases due to the presence of repeat sequences present at the recombination site and, therefore, the PAR boundary may be different between the consomic strains (Kipling et al. 1996a,b). A dramatic example of a boundary shift arising in radiation-induced mutation rate studies at Oak Ridge National Laboratory is seen in $\mathrm{ChrY}^{\text {yaa }}$ ("Y-linked autoimmune accelerator") (Major 1954; Lane and Murphy 1972) whose PAR is extended by $>4$ megabases $(\mathrm{Mb})$ and contains $\sim 19$ additional genes that translocated from ChrX (Pisitkun et al. 2006; Subramanian et al. 2006; Santiago-Raber et al. 2008). However, we did not detect any significant expression level differences in genes residing within $10 \mathrm{Mb}$ of the PAR boundary in our microarray studies comparing B6-ChrY ${ }^{\mathrm{SJL}}$ vs. B6 CD4 ${ }^{+}$T cells or SJL-ChrY ${ }^{\mathrm{B} 10.5}$ vs. SJL CD4 ${ }^{+} \mathrm{T}$ cells and macrophages, suggesting that the phenotypic differences observed in these consomic strains are not the result of a similar expansion in the PAR.

Only when we have obtained a detailed understanding of the regulatory genome will we be able to fully appreciate the mechanistic setting underlying complex disease traits. The recent unveiling of the ENCyclopedia Of DNA Elements (ENCODE) project has enlightened the scientific community on the vast wealth of information residing in non-protein coding DNA sequences (The ENCODE Project Consortium 2012). Our investigation into gene regulation by ChrY lends significance to what was once considered to be "junk" DNA and defies the belief that in mammals ChrY's contribution to sexual dimorphisms is limited to sexual differentiation, development, and associated male sex hormones. A comparison of the myocarditis heart score and the clinical EAE disease course of female mice with male B6-ChrY consomic strains indicates that sexual dimorphisms can be contextually dependent upon the cell type-specific genome-wide trans-eQTL properties of ChrY. Clearly, defining the epigenetic mechanisms whereby ChrY polymorphism influences the regulatory genome in human health and disease, and the role that such polymorphism plays in sexual dimorphism (Mank 2009; Parsch and Ellegren 2013), is critical for the appropriate therapeutic management of complex diseases.

\section{Methods}

\section{Mice}

All mice in this study were bred and maintained in the animal facility at the University of Vermont. The B6-ChrY consomic panel of mice used in this study was purchased from The Jackson Laboratory. The number of backcrosses preformed prior to cryopreservation is indicated next to each strain if this information was available on The Jackson Lab website. We then backcrossed each consomic strain to $\mathrm{B} 6$ at least one more time before conducting the experiments. C57BL/6J (B6), C57BL/6J-ChrY ${ }^{12951 / 5 v I m J} / \mathrm{NaJ}(\mathrm{B} 6-$

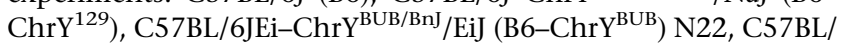
6JEi-ChrY ${ }^{\mathrm{A} / \mathrm{J}} / \mathrm{EiJ}\left(\mathrm{B} 6-\mathrm{ChrY}^{\mathrm{AJ}}\right) \mathrm{N} 17, \mathrm{C} 57 \mathrm{BL} / 6 \mathrm{JEi}-\mathrm{ChrY}^{\mathrm{LEWES}} / \mathrm{EiJ}(\mathrm{B} 6-$ $\mathrm{ChrY}^{\mathrm{LEWES}}$ ) N33, C57BL/6-ChrY ${ }^{\mathrm{PWD} / \mathrm{Ph}} /$ ForeJ (B6-ChrY ${ }^{\mathrm{PWD}}$ ) N14, C57BL/6JEi-ChrY ${ }^{\mathrm{RF} / \mathrm{J}} / \mathrm{EiJ}\left(\mathrm{B} 6-\mathrm{ChrY}{ }^{\mathrm{RF}}\right) \mathrm{N} 22, \mathrm{C} 57 \mathrm{BL} / 6 \mathrm{JEi}-\mathrm{ChrY} \mathrm{SJL}^{\mathrm{S} /}$ / EiJ $\left(\mathrm{B} 6-\mathrm{ChrY}^{\mathrm{SJL}}\right) \mathrm{N} 20, \mathrm{C} 57 \mathrm{BL} / 6 \mathrm{JEi}-\mathrm{ChrY}^{\mathrm{ST} / \mathrm{bJ}} / \mathrm{EiJ}\left(\mathrm{B} 6-\mathrm{ChrY}^{\mathrm{ST}}\right)$

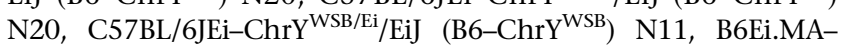

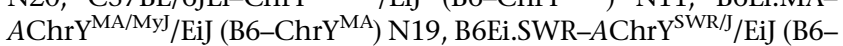
$\mathrm{ChrY}^{\mathrm{SWR}}$ ) N20. SJL-ChrY ${ }^{\mathrm{B} 10 . \mathrm{S}}$ mice were generated at the University of Vermont and backcrossed for a minimum of 15 generations and are available at The Jackson Laboratory (SJL/J-ChrY $\left.{ }^{\mathrm{B} 10} / \mathrm{TeuJ}\right) . \mathrm{SJL} / \mathrm{J}$ mice were purchased from The Jackson Laboratory (Bar Harbor, ME). Animals were housed in specific pathogen-free conditions under National Institutes of Health guidelines, and all experiments performed in this study were approved by the Animal Care and Use Committee of the University of Vermont.

\section{Induction and evaluation of EAE}

Mice were immunized for the induction of EAE using the doubleinoculation $(2 \times)$ protocol and scored as previously described (Noubade et al. 2007) and for SJL (Spach et al. 2009). Histopathological evaluations were done as previously described (Teuscher et al. 2004).

\section{Induction and evaluation of myocarditis}

The H3 variant of CVB3 was made from an infectious cDNA clone as previously described (Knowlton et al. 1996). Mice were infected by intraperitoneal injection of $0.5 \mathrm{~mL}$ of PBS containing $50 \mathrm{PFU}$ CVB3 and euthanized $7 \mathrm{~d}$ after infection. Hearts were fixed in 10\% buffered formalin, paraffin-embedded, sectioned, and stained with haematoxylin and eosin. Sections were blindly evaluated on a 0-4 scale, with 0 representing no inflammation, 1 indicating 1-10 lesions, 2 indicating 11-20 lesions, 3 indicating 21-40 lesions, and 4 indicating $>40$ lesions per section.

\section{Heart viral titers}

Hearts were homogenized in RPMI-1640 media (Mediatech) containing $2 \%$ FCS, penicillin, and streptomycin. Cellular debris was removed by centrifugation at $300 \mathrm{~g}$ for $10 \mathrm{~min}$ and supernatants subjected to a series of 10 -fold serial dilutions in above media. Titers were determined by plaque forming assay as previously described (Knowlton et al. 1996).

\section{Serum testosterone}

Eight-week-old mice were bled by tail vein and the samples spun down for $20 \mathrm{~min}$ at $16,000 \mathrm{~g}$ to extract serum. Samples were stored at $-80^{\circ} \mathrm{C}$. Serum testosterone levels were measured using a testosterone enzyme immunoassay (EIA) kit according to the manufacturer's instructions (Assay Designs). Briefly, serum samples were diluted with 1 part steroid displacement reagent for every 99 parts sample. Each sample was diluted 1:10 and 1:20 in PBS and added to the 96-well plate in duplicate, followed by the primary antibody, and incubated at room temperature for $1 \mathrm{~h}$ while shaking. Wells were washed and conjugate was added to each well and incubated at room temperature for $1 \mathrm{~h}$ while shaking. Wells were washed and the pNpp substrate was added to each well and incubated at $37^{\circ} \mathrm{C}$

\section{Genome Research www.genome.org}


for $1 \mathrm{~h}$ without shaking. Stop solution was added and the plate read immediately with optical density at $405 \mathrm{~nm}$.

\section{FACS-purified $\mathrm{CD}^{+} \mathrm{T}$ cells}

Three biological replicates were pooled from the axillary, brachial, and inguinal lymph nodes from five mice for each replicate. Cells were washed with PBS $/ 1 \% \mathrm{FCS}$, pelleted at $300 \mathrm{~g}$ for $5 \mathrm{~min}$ at $4^{\circ} \mathrm{C}$. A working stock of Live/Dead-775 dye (Invitrogen L10119) was made by adding $1 \mu \mathrm{L}$ of reconstituted dye to $1 \mathrm{~mL}$ PBS and cells were resuspended in $100 \mu \mathrm{L}$ of working stock per $1 \times 10^{6}$ cells. Cells were incubated for $30 \mathrm{~min}$ on ice in the dark. Cells were washed with cold PBS/1\% FCS, pelleted, and resuspended in $100 \mu \mathrm{L}$ of an antibody mixture containing $1 \mu \mathrm{g} / \mathrm{mL}$ PerCp-Cy5.5 anti-mouse TCR $\beta$ chain and $1 \mu \mathrm{g} / \mathrm{mL}$ Alexa Flour 488 anti-mouse CD4 antibodies in PBS/1\% FCS. Cells were incubated on ice in the dark for 30 min then washed with cold PBS/1\% FCS, pelleted, and resuspended at a concentration of $10 \times 10^{6}$ cells per $1 \mathrm{~mL}$ of $\mathrm{PBS} / 10 \%$ FCS. Cells were filtered through $50 \mu \mathrm{m}$ nylon mesh and sorted using BD FACSAria to collect $\sim 3 \times 10^{6} \mathrm{CD}^{+} \mathrm{T}$ cells per sample.

\section{Adherent macrophages}

Adherent macrophages were isolated in culture from thioglycollateelicited peritoneal exudate cells as previously described (Zhang et al. 2008). For each strain, three pooled biological replicates of adherent macrophages were obtained from five mice for each pool.

\section{RNA isolation}

RNA was isolated using the Qiagen RNeasy Plus Mini Kit following the manufacturer's instructions (Qiagen). RNA was eluted using $30 \mu \mathrm{L}$ RNase-free $\mathrm{H}_{2} \mathrm{O}$ and $0.5 \mu \mathrm{L}$ Superase (Life Technologies) was added to each sample. RNA was quantitated on ND 1000 spectrophotometer v.3.3.1 (ThermoScientific) and quality assessed on a 2100 Bioanalyzer (Agilent). RNA was stored at $-80^{\circ} \mathrm{C}$ and submitted to the Vermont Genetics Network Microarray Facility.

\section{Mouse gene array target preparation}

Oligonucleotide microarray analysis of RNA expression levels was performed in the Vermont Genetics Network Microarray Facility using the Affymetrix GeneChip Platform (Affymetrix Inc.) according to manufacturer's protocols. In brief, the Nugen Ovation system v. 2 with SPIA RNA amplification was employed to convert $50 \mathrm{ng}$ of total RNA to cDNA. This isothermal RNA amplification system produces 5-12 $\mu \mathrm{g}$ of anti-sense cDNA targets that is followed by several steps to produce sense strand cDNA to be fragmented, biotinylated, and hybridized to the genechip. After purification and fragmentation, biotinylated-cDNA targets were hybridized to the Mouse Gene 1.0 ST Arrays oligonucleotide arrays for $16 \mathrm{~h}$ at $45^{\circ} \mathrm{C}$. Hybridized arrays were washed and stained with streptavidin-phycoerythrin followed by sequential incubations with biotin-coupled polyclonal anti-streptavidin antibody and streptavidin-phycoerythrin as a fluorescent amplification step. After staining, arrays were scanned (3000-7G Scanner, Affymetrix Inc.) and data collected for statistical analysis.

\section{Mouse miRNA array target preparation}

Total RNA containing small RNA was labeled using the FlashTag RNA labeling kit (Genisphere) and performed in the Vermont Genetics Network Microarray Facility according to the manufacturer's instructions. Briefly, for each sample, $500 \mathrm{ng}$ of total RNA was subjected to a tailing reaction $(2.5 \mathrm{mM} \mathrm{MnCl} 2$, ATP, Poly A Polymerase-incubation for $15 \mathrm{~min}$ at $37^{\circ} \mathrm{C}$ ) followed by ligation of the biotinylated signal molecule to the target RNA sample $(1 \times$ FlashTag ligation mix biotin, T4 DNA ligase-incubation for $30 \mathrm{~min}$ at $25^{\circ} \mathrm{C}$ ) and addition of HSR stop solution. Each sample was hybridized to a GeneChip miRNA 2.0 Array (Affymetrix) at $48^{\circ} \mathrm{C}$ and $60 \mathrm{rpm}$ for $16 \mathrm{~h}$ then washed and stained on Fluidics Station 450 (Fluidics script FS450_0003) and finally scanned on a GeneChip Scanner 3000-7G (Affymetrix).

\section{Calculation of probe set statistics}

Raw GeneChip data (one DAT file for each chip) includes a collection of images, one for each probe and chip. Each image was summarized by Affymetrix GCOS software using one probe intensity (in CEL files, one per chip). Information from multiple probes was combined to obtain a single measure of expression for each probe set and sample. Probe-level intensities were calculated using the Robust Multichip Average (RMA) algorithm, including background correction, normalization (quantile), and summarization (median polish), for each probe set and sample, as is implemented in Partek Genomic Suite, version 6.6 (Partek Inc., St. Louis, $\mathrm{MO})$. Sample quality was assessed based on the relative log expression (RLE), and normalized unscaled standard error (NUSE). Principal Component Analysis (PCA) was also used to look for outlier samples that would potentially introduce latent variation into the analysis of differential expression across sample groups. Linear modeling of sample groups and identification of alternatively spliced variants were performed using ANOVA as implemented in Partek Genomic Suite. The magnitude of the response (fold change calculated using the least square mean) and the $P$-value associated with each probe set and binary comparison were calculated, as well as step-up, adjusted $P$-value for the purpose of controlling the false discovery rate (Benjamini and Hochberg 1995).

\section{Bioinformatic analyses}

Data were analyzed through the use of the Mouse Genome Informatics Gene Ontology Term Finder (www.informatics.jax.org/ gotools/MGI_Term_Finder.html) and by Ingenuity Pathways Analysis (Ingenuity Systems, www.ingenuity.com).

\section{$\mathrm{CD}^{+}{ }^{+}$T-cell activation and ELISA}

Three biological replicates of $\mathrm{CD}^{+} \mathrm{T}$ cells were purified from axillary, brachial, and inguinal lymph nodes pooled from five mice using the EasySep mouse $\mathrm{CD}^{+}$T-cell enrichment kit and EasySep magnet following the manufacturer's instructions (Stemcell Technologies). Nonpolarized effector T cells were generated as previously described (Noubade et al. 2007). Supernatants were removed after 24,48 , and $72 \mathrm{~h}$ and frozen at $-80^{\circ} \mathrm{C}$ until cytokine levels were tested by ELISA.

\section{Quantitative PCR array}

Three biological replicates of $\mathrm{CD} 4^{+} \mathrm{T}$ cells were purified from axillary, brachial, and inguinal lymph nodes pooled from five mice using the EasySep mouse $\mathrm{CD} 4^{+}$T-cell enrichment kit and EasySep magnet following the manufacturer's instructions (Stemcell Technologies). High-quality RNA was isolated, tested for gDNA contamination, and hybridized to the $\mathrm{RT}^{2}$ Profiler 96-well PCR array (PAMM-086Z) run on Applied Biosystems 7900HT standard block real-time cycler by the Vermont Genetics Network DNA analysis facility at the University of Vermont. Data were analyzed using ABI Prism SDS 2.1 software (Life Technologies) followed by the RT ${ }^{2}$ Profiler PCR Array Data Analysis Version 3.5 (SABiosciences). 


\section{Gene copy number assay}

Tail DNA was isolated from a minimum of five male mice from each B6-ChrY consomic line and WT B6. DNA was quantified by Nanodrop and diluted to $5 \mathrm{ng} / \mu \mathrm{L}$ in nuclease-free $\mathrm{H}_{2} \mathrm{O}$. FAM dyelabeled PCR primers for $S l y, R b m y$, and Ssty 1 were designed using the Custom Taqman Assay Design Tool on the Life Technologies website by entering the DNA sequence obtained from MGI. VIC dye-labeled mouse Tfrc Taqman Copy Number Reference Assay was used in the duplex real-time PCR reaction and run on the 7500 realtime PCR system according to the manufacturer's instructions. Data were analyzed using ABI Prism SDS 2.1 software followed by the CopyCaller Software Version 2.0 (Life Technologies). WT B6 was used as the reference strain and set to 10 copies for each of the genes.

\section{Data access}

The microarray data discussed in this manuscript have been deposited in the NCBI Gene Expression Omnibus (GEO; http:// www.ncbi.nlm.nih.gov/geo/) (Edgar et al. 2002) under accession number GSE47440.

\section{Acknowledgments}

This work was funded by NIH Grants NS061014 (C.T. and E.P.B.), AI45666 (C.T. and S.A.H.), HL108371 (S.A.H.); Myocarditis Foundation Research Fellowship Grant (L.K.C.); and the Vermont Genetics Network through Grant Number P20RR16462 and 8P20GM103449 from the INBRE Program of the NCRR and NIGMS, respectively. We thank Drs. Mercedes Rincon, Sean A. Diehl, Roxana del Rio, and Jeffery Bond for helpful discussion; and The Vermont Cancer Center's DNA Analysis Facility and Microarray Facility, including Timothy Hunter and Mary Louise Shane, for their microarray and qPCR expertise.

\section{References}

Albrecht KH, Young M, Washburn LL, Eicher EM. 2003. Sry expression level and protein isoform differences play a role in abnormal testis development in C57BL/6J mice carrying certain Sry alleles. Genetics 164: $277-288$.

Alfoldi J. 2008. "Sequencing the mouse Y chromosome." PhD thesis, Massachusetts Institute of Technology, Cambridge.

Arnold AP. 2012. The end of gonad-centric sex determination in mammals. Trends Genet 28: 55-61.

Arnold AP, Chen XQ. 2009. What does the "four core genotypes" mouse model tell us about sex differences in the brain and other tissues? Front Neuroendocrinol 30: $1-9$

Arnold AP, Lusis AJ. 2012. Understanding the sexome: Measuring and reporting sex differences in gene systems. Endocrinology 153: 25512555.

Bebo BF Jr, Zelinka-Vincent E, Adamus G, Amundson D, Vandenbark AA, Offner H. 1998. Gonadal hormones influence the immune response to PLP 139-151 and the clinical course of relapsing experimental autoimmune encephalomyelitis. J Neuroimmunol 84: 122-130.

Benjamini Y, Hochberg Y. 1995. Controlling the False Discovery Rate: A practical and powerful approach to multiple testing. J R Stat Soc Series B 57: 289-300.

Bhasin JM, Chakrabarti E, Peng DQ, Kulkarni A, Chen X, Smith JD. 2008. Sex specific gene regulation and expression QTLs in mouse macrophages from a strain intercross. PLOS ONE 3: e1435.

Burgoyne PS, Ojarikre OA, Turner JMA. 2002. Evidence that postnatal growth retardation in $\mathrm{XO}$ mice is due to haploinsufficiency for a nonPAR X gene. Cytogenet Genome Res 99: 252-256.

Case LK, Toussaint L, Moussawi M, Roberts B, Saligrama N, Brossay L, Huber SA, Teuscher C. 2012. Chromosome Y regulates survival following murine coxsackievirus B3 infection. G3-Genes Genom Genet 2: 115-121.

Castle WE. 1914. Multiple factors in heredity. Science 39: 686-689.

Charchar FJ, Bloomer LD, Barnes TA, Cowley MJ, Nelson CP, Wang Y, Denniff M, Debiec R, Christofidou P, Nankervis S, et al. 2012.
Inheritance of coronary artery disease in men: An analysis of the role of the Y chromosome. Lancet 379: 915-922.

Charlesworth B. 1991. The evolution of sex chromosomes. Science 251: 1030-1033.

Chen XQ, McClusky R, Itoh Y, Reue K, Arnold AP. 2013. X and Y chromosome complement influence adiposity and metabolism in mice. Endocrinology 154: 1092-1104.

Cocquet J, Ellis PJ, Yamauchi Y, Mahadevaiah SK, Affara NA, Ward MA, Burgoyne PS. 2009. The multicopy gene Sly represses the sex chromosomes in the male mouse germline after meiosis. PLoS Biol 7: e1000244.

Cocquet J, Ellis PJI, Mahadevaiah SK, Affara NA, Vaiman D, Burgoyne PS. 2012. A genetic basis for a postmeiotic X versus $Y$ chromosome intragenomic conflict in the mouse. PLoS Genet 8: e1002900.

Corvol JC, Pelletier D, Henry RG, Caillier SJ, Wang J, Pappas D, Casazza S, Okuda DT, Hauser SL, Oksenberg JR, et al. 2008. Abrogation of T cell quiescence characterizes patients at high risk for multiple sclerosis after the initial neurological event. Proc Natl Acad Sci 105: 11839-11844.

Cua DJ, Hinton DR, Stohlman SA. 1995. Self-antigen-induced Th2 responses in experimental allergic ancephalomyelitis (EAE)-resistant mice. I Immunol 155: 4052-4059.

Dimitri P, Pisano C. 1989. Position effect variegation in Drosophila melanogaster: Relationship between suppression effect and the amount of Y chromosome. Genetics 122: 793-800.

East EM. 1916. Studies on size inheritance in Nicotiana. Genetics 1: 164-176.

Edgar R, Domrachev M, Lash AE. 2002. Gene Expression Omnibus: NCBI gene expression and hybridization array data repository. Nucleic Acids Res 30: 207-210.

Elliott DJ, Ma K, Kerr SM, Thakrar R, Speed R, Chandley AC, Cooke H. 1996. An RBM homologue maps to the mouse Y chromosome and is expressed in germ cells. Hum Mol Genet 5: 869-874.

Elliott DJ, Bourgeois CF, Klink A, Stevenin J, Cooke HJ. 2000. A mammalian germ cell-specific RNA-binding protein interacts with ubiquitously expressed proteins involved in splice site selection. Proc Natl Acad Sci 97: 5717-5722.

Ellis PJI, Bacon J, Affara NA. 2011. Association of Sly with sex-linked gene amplification during mouse evolution: A side effect of genomic conflict in spermatids? Hum Mol Genet 20: 3010-3021.

The ENCODE Project Consortium. 2012. An integrated encyclopedia of DNA elements in the human genome. Nature 489: 57-74.

Fairweather D, Cooper LT Jr, Blauwet LA. 2013. Sex and gender differences in myocarditis and dilated cardiomyopathy. Curr Probl Cardiol 38: 7-46.

Fillmore PD, Blankenhorn EP, Zachary JF, Teuscher C. 2004. Adult gonadal hormones selectively regulate sexually dimorphic quantitative traits observed in experimental allergic encephalomyelitis. Am J Pathol 164: $167-175$.

Frisancho-Kiss S, Coronado MJ, Frisancho JA, Lau VM, Rose NR, Klein SL, Fairweather D. 2009. Gonadectomy of male BALB/c mice increases Tim$3^{+}$alternatively activated M2 macrophages, Tim $-3^{+}$T cells, Th2 cells and Treg in the heart during acute coxsackievirus-induced myocarditis. Brain Behav Immun 23: 649-657.

Gauntt C, Huber S. 2003. Coxsackievirus experimental heart diseases. Front Biosci 8: e23-e35.

Gschwend AR, Weingartner LA, Moore RC, Ming R. 2012. The sex-specific region of sex chromosomes in animals and plants. Chromosome Res 20: $57-69$.

Huber SA, Job LP, Auld KR. 1982. Influence of sex hormones on Coxsackie B3 virus infection in Balb/c mice. Cell Immunol 67: 173-179.

Huttunen S, Aspi J. 2003. Complex inheritance of male courtship song characters in Drosophila virilis. Behav Genet 33: 17-24.

Kipling D, Salido EC, Shapiro LJ, Cooke HJ. 1996a. High frequency de novo alterations in the long-range genomic structure of the mouse pseudoautosomal region. Nat Genet 13: 78-80.

Kipling D, Wilson HE, Thomson EJ, Lee M, Perry J, Palmer S, Ashworth A Cooke HJ. 1996b. Structural variation of the pseudoautosomal region between and within inbred mouse strains. Proc Natl Acad Sci 93: 171175.

Knowlton KU, Jeon ES, Berkley N, Wessely R, Huber S. 1996. A mutation in the puff region of VP2 attenuates the myocarditic phenotype of an infectious cDNA of the Woodruff variant of coxsackievirus B3. J Virol 70: 7811-7818.

Koerich LB, Wang X, Clark AG, Carvalho AB. 2008. Low conservation of gene content in the Drosophila Y chromosome. Nature 456: 949-951.

Lane PW, Murphy ED. 1972. Susceptibility to spontaneous pneumonitis in an inbred strain of beige and satin mice. Genetics 72: 451-460.

Lemos B, Araripe LO, Hartl DL. 2008. Polymorphic Y chromosomes harbor cryptic variation with manifold functional consequences. Science $\mathbf{3 1 9}$ : 91-93.

Lemos B, Branco AT, Hartl DL. 2010. Epigenetic effects of polymorphic Y chromosomes modulate chromatin components, immune response, and sexual conflict. Proc Natl Acad Sci 107: 15826-15831.

\section{Genome Research}


Luco RF, Allo M, Schor IE, Kornblihtt AR, Misteli T. 2011. Epigenetics in alternative pre-mRNA splicing. Cell 144: 16-26.

Lyden DC, Olszewski J, Feran M, Job LP, Huber SA. 1987. Coxsackievirus B-3induced myocarditis. Effect of sex steroids on viremia and infectivity of cardiocytes. Am J Pathol 126: 432-438.

Major MH. 1954. Mouse News Letter 12: 47.

Mank JE. 2009. Sex chromosomes and the evolution of sexual dimorphism: Lessons from the genome. Am Nat 173: 141-150.

McCombe PA, Greer JM, Mackay IR. 2009. Sexual dimorphism in autoimmune disease. Curr Mol Med 9: 1058-1079.

Monahan EJ, Maxson SC. 1998. Y chromosome, urinary chemosignals, and an agonistic behavior (offense) of mice. Physiol Behav 64: 123-132.

Nadeau JH, Forejt J, Takada T, Shiroishi T. 2012. Chromosome substitution strains: Gene discovery, functional analysis, and systems studies. Mamm Genome 23: 693-705.

Nagamine CM, Morohashi K, Carlisle C, Chang DK. 1999. Sex reversal caused by Mus musculus domesticus $\mathrm{Y}$ chromosomes linked to variant expression of the testis-determining gene Sry. Dev Biol 216: 182-194.

Navarro-Costa P, Plancha CE, Goncalves J. 2010. Genetic dissection of the AZF regions of the human Y chromosome: Thriller or filler for male (in)fertility? J Biomed Biotechnol 2010: 936569.

Noubade R, Milligan G, Zachary JF, Blankenhorn EP, del Rio R, Rincon M, Teuscher C. 2007. Histamine receptor H1 is required for TCR-mediated p38 MAPK activation and optimal IFN- $\gamma$ production in mice. J Clin Invest 117: $3507-3518$.

Ober C, Loisel DA, Gilad Y. 2008. Sex-specific genetic architecture of human disease. Nat Rev Genet 9: 911-922.

Papenfuss TL, Rogers CJ, Gienapp I, Yurrita M, McClain M, Damico N, Valo J Song F, Whitacre CC. 2004. Sex differences in experimental autoimmune encephalomyelitis in multiple murine strains. J Neuroimmunol 150: 59-69.

Paredes S, Branco AT, Hartl DL, Maggert KA, Lemos B. 2011. Ribosomal DNA deletions modulate genome-wide gene expression: "rDNA-sensitive" genes and natural variation. PLoS Genet 7: e1001376.

Parsch J, Ellegren H. 2013. The evolutionary causes and consequences of sex-biased gene expression. Nat Rev Genet 14: 83-87.

Pennell LM, Galligan CL, Fish EN. 2012. Sex affects immunity. J Autoimmun 38: J282-J291.

Perry J, Palmer S, Gabriel A, Ashworth A. 2001. A short pseudoautosomal region in laboratory mice. Genome Res 11: 1826-1832.

Piergentili R. 2010. Multiple roles of the Y chromosome in the biology of Drosophila melanogaster. ScientificWorldJournal 10: 1749-1767.

Pisitkun P, Deane JA, Difilippantonio MJ, Tarasenko T, Satterthwaite AB, Bolland S. 2006. Autoreactive B cell responses to RNA-related antigens due to TLR7 gene duplication. Science 312: 1669-1672.

Reynard LN, Cocquet J, Burgoyne PS. 2009. The multi-copy mouse gene Sycp3-like Y-linked (Sly) encodes an abundant spermatid protein that interacts with a histone acetyltransferase and an acrosomal protein. Biol Reprod 81: 250-257.

Robinson DP, Huber SA, Moussawi M, Roberts B, Teuscher C, Watkins R, Arnold AP, Klein SL. 2011. Sex chromosome complement contributes to sex differences in coxsackievirus B3 but not influenza A virus pathogenesis. Biol Sex Differ 2: 8 .

Santiago-Raber ML, Kikuchi S, Borel P, Uematsu S, Akira S, Kotzin BL, Izui S 2008. Evidence for genes in addition to Tlr7 in the Yaa translocation linked with acceleration of systemic lupus erythematosus. I Immunol 181: $1556-1562$.

Skaletsky H, Kuroda-Kawaguchi T, Minx PJ, Cordum HS, Hillier L, Brown LG, Repping S, Pyntikova T, Ali J, Bieri T, et al. 2003. The male-specific region of the human Y chromosome is a mosaic of discrete sequence classes. Nature 423: 825-837.

Skrisovska L, Bourgeois CF, Stefl R, Grellscheid SN, Kister L, Wenter P, Elliott DJ, Stevenin J, Allain FHT. 2007. The testis-specific human protein RBMY recognizes RNA through a novel mode of interaction. EMBO Rep 8: $372-379$.

Smith-Bouvier DL, Divekar AA, Sasidhar M, Du S, Tiwari-Woodruff SK, King JK, Arnold AP, Singh RR, Voskuhl RR. 2008. A role for sex chromosome complement in the female bias in autoimmune disease. J Exp Med 205: 1099-1108.
Spach KM, Blake M, Bunn JY, McElvany B, Noubade R, Blankenhorn EP, Teuscher C. 2009. Cutting edge: The Y chromosome controls the agedependent experimental allergic encephalomyelitis sexual dimorphism in SJL/J mice. J Immunol 182: 1789-1793.

Spence RD, Voskuhl RR. 2012. Neuroprotective effects of estrogens and androgens in CNS inflammation and neurodegeneration. Front Neuroendocrinol 33: 105-115.

Stohlman SA, Matsushima GK, Casteel N, Frelinger JA. 1985. The defect in delayed-type hypersensitivity of young adult SJL mice is due to a lack of functional antigen-presenting cells. Eur J Immunol 15: 913-916.

Stoltenberg SF, Hirsch J. 1997. Y-chromosome effects on Drosophila geotaxis interact with genetic or cytoplasmic background. Anim Behav 53: 853-864.

Styrna J, Imai HT, Moriwaki K. 1991a. An increased level of sperm abnormalities in mice with a partial deletion of the Y chromosome. Genet Res 57: 195-199.

Styrna J, Klag J, Moriwaki K. 1991b. Influence of partial deletion of the Y chromosome on mouse sperm phenotype. J Reprod Fertil 92: 187-195.

Subramanian S, Tus K, Li QZ, Wang A, Tian XH, Zhou J, Liang C, Bartov G, McDaniel LD, Zhou XJ, et al. 2006. A Tlr7 translocation accelerates systemic autoimmunity in murine lupus. Proc Natl Acad Sci 103: 9970 9975.

Sun SL, Horino S, Itoh-Nakadai A, Kawabe T, Asao A, Takahashi T, So T, Funayama R, Kondo M, Saitsu H, et al. 2013. Y chromosome-linked B and NK cell deficiency in mice. J Immunol 190: 6209-6220.

Szot M, Grigoriev V, Mahadevaiah SK, Ojarikre OA, Tour A, von Glasenapp E, Rattigan A, Turner JMA, Elliott DJ, Burgoyne PS. 2003. Does Rbmy have a role in sperm development in mice? Cytogenet Genome Res 103: 330336.

Teuscher C, Bunn JY, Fillmore PD, Butterfield RJ, Zachary JF, Blankenhorn EP. 2004. Gender, age, and season at immunization uniquely influence the genetic control of susceptibility to histopathological lesions and clinical signs of experimental allergic encephalomyelitis: Implications for the genetics of multiple sclerosis. Am J Pathol 165: 1593-1602.

Teuscher C, Noubade R, Spach K, McElvany B, Bunn JY, Fillmore PD, Zachary JF, Blankenhorn EP. 2006. Evidence that the Y chromosome influences autoimmune disease in male and female mice. Proc Natl Acad Sci 103: 8024-8029.

Tiepolo L, Zuffardi O. 1976. Localization of factors controlling spermatogenesis in the nonfluorescent portion of the human $\mathrm{Y}$ chromosome long arm. Hum Genet 34: 119-124.

Toure A, Clemente EJ, Ellis P, Mahadevaiah SK, Ojarikre OA, Ball PA, Reynard L, Loveland KL, Burgoyne PS, Affara NA. 2005. Identification of novel Y chromosome encoded transcripts by testis transcriptome analysis of mice with deletions of the Y chromosome long arm. Genome Biol 6: R102.

Washburn LL, Albrecht KH, Eicher EM. 2001. C57BL/6J-T-associated sex reversal in mice is caused by reduced expression of a Mus domesticus Sry allele. Genetics 158: $1675-1681$.

Wesley JD, Tessmer MS, Paget C, Trottein F, Brossay L. 2007. A Y chromosome-linked factor impairs NK T development. J Immunol 179: 3480-3487.

White MA, Ikeda A, Payseur BA. 2012. A pronounced evolutionary shift of the pseudoautosomal region boundary in house mice. Mamm Genome 23: $454-466$

Zeng M, Sun H, Chen S, Wang X, Yang Y, Liu Y, Tao D, Yang Z, Zhang S, Ma Y. 2008. Identification of target messenger RNA substrates for mouse RBMY. Mol Hum Reprod 14: 331-336.

Zhang X, Goncalves R, Mosser DM. 2008. The isolation and characterization of murine macrophages. Curr Protoc Immunol 83: 14.1.1-14.1.14.

Zhou J, Sackton TB, Martinsen L, Lemos B, Eickbush TH, Hartl DL. 2012. Y chromosome mediates ribosomal DNA silencing and modulates the chromatin state in Drosophila. Proc Natl Acad Sci 109: 9941-9946.

Received February 22, 2013; accepted in revised form June 19, 2013. 


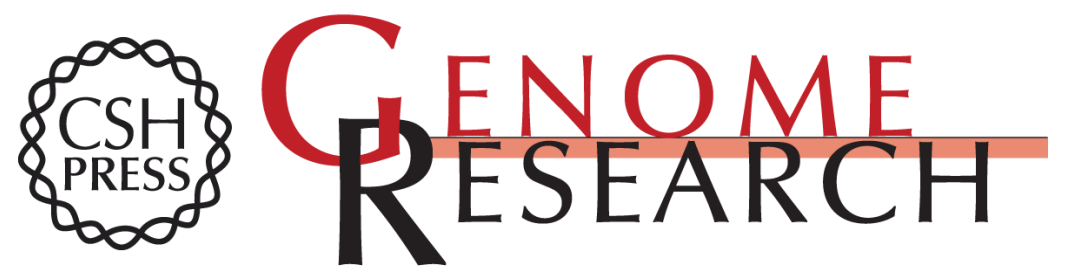

\section{The $\mathrm{Y}$ chromosome as a regulatory element shaping immune cell transcriptomes and susceptibility to autoimmune disease}

Laure K. Case, Emma H. Wall, Julie A. Dragon, et al.

Genome Res. 2013 23: 1474-1485 originally published online June 25, 2013

Access the most recent version at doi:10.1101/gr.156703.113

Supplemental Material

References

Creative

Commons

License

Email Alerting Service
http://genome.cshlp.org/content/suppl/2013/07/11/gr.156703.113.DC1

This article cites 81 articles, 25 of which can be accessed free at: http://genome.cshlp.org/content/23/9/1474.full.html\#ref-list-1

This article is distributed exclusively by Cold Spring Harbor Laboratory Press for the first six months after the full-issue publication date (see

http://genome.cshlp.org/site/misc/terms.xhtml). After six months, it is available under a Creative Commons License (Attribution-NonCommercial 3.0 Unported), as described at http://creativecommons.org/licenses/by-nc/3.0/.

Receive free email alerts when new articles cite this article - sign up in the box at the top right corner of the article or click here.

\section{Affordable, Accurate Sequencing.}

To subscribe to Genome Research go to:

https://genome.cshlp.org/subscriptions 